\title{
O Papel da História da Exploração Aurífera em Ouro Preto e a Formação de Professores de Geologia
}

\author{
Messias Gilmar de Menezes (messias@degeo.ufop.br) \\ Departamento de Geologia - UFOP \\ Campus Morro do Cruzeiro, CEP 35400-000, Ouro Preto, MG, BRA \\ Recebido em 15 de julho de 2004; aceito em 29 de novembro de 2004
}

Palavras-chave: História da Ciência, textos históricos, atividades didáticas, exploração aurífera.

\section{RESUMO}

A reflexão sobre a realidade em que se dá o ensino de Ciências no Brasil nos mostra uma forte ênfase em atividades docentes que procuram dotar os egressos de habilidades e competências próximas da de um cientista. Este fato não é prerrogativa apenas nossa. Autores familiarizados com outros padrões culturais discutem este tema. Sugerem uma mudança no enfoque para o ensino de Ciências. O ensino de Geologia, aqui entre nós, privilegia em sala de aula "o relato da prática científica, apresentado pelos livros-texto”. Geralmente é apresentada uma Ciência idealizada, ou então, bem menos comum, uma forte ênfase é dada ao ensino de Geologia de campo e práticas experimentais onde o experimento e os seus resultados são apresentados ao aluno como auto-evidentes. Com o objetivo de discutir com potenciais professores de Geologia em cursos de nível médio e nos primeiros semestres da Universidade, o papel da Epistemologia e da História da Geologia no ensino desta Ciência, e de sugerir alternativas de como ensinar, foi proposto um estudo, dentro da disciplina "Metodologia de Ensino da Geologia” - do Curso de Especialização em Gemologia, no DEGEO/UFOP. Para isso, foi planejada uma unidade de ensino relativo à aplicação da História da Geologia ao ensino. O propósito do presente trabalho é apresentar os resultados da análise feita do processo de ensino proposto. A escolha da história da exploração aurífera em Ouro Preto como objeto privilegiado para a construção de atividades facilitou a compreensão das metodologias de produção do conhecimento científico geológico, assim como ampliou as possibilidades de compreensão do papel da Epistemologia e História da Geologia para o ensino desta Ciência.

Keywords: History of Science, historical texts, didactic activities, gold exploration.

\section{ABSTRACT}

Reflections on the reality of Science teaching in Brazil show us that teachers put strong emphasis on subjects that ultimately lead to the formation of professionals with certain skills and competence characteristic of a scientist. However, this is not an aspect that is exclusive to Brazil. Geology teaching in Brazil is mostly focused on the reporting of scientific practice found in textbooks. Generally, Science is presented in an idealized manner or, less frequently, with great emphasis on field geology or on experiments presented to the students as self-evident. Authors with knowledge of other cultures have discussed this subject. They suggest changes in the emphasis of Science teaching in those cultures. The main goal of this study is to promote a broad debate, between teachers from high school to elementary university levels, on the role of epistemology and the history of Geology in the teaching of Science, as well as to suggest alternative ways of teaching. This is the scope of the discipline "Methodology of geological teaching", which discipline is part of the specialization course in Gemology, offered by the Department of Geology of the Federal University of Ouro Preto. To reach that goal we have designed a unit of teaching using the history of geology as a base in the teaching of Science. In this paper we present the results of this experience. We took an example from the history of gold exploration in the town of Ouro Preto, to illustrate the manner through which those activities promoted knowledgement, to understand the evolution of the methods applied in the geological sciences as well as the role of epistemology and the history of geology on the teaching of geological sciences. 


\section{INTRODUÇÃO}

O propósito do presente trabalho é apresentar os resultados da análise feita do processo de ensino proposto e executado no Curso de Metodologia de Ensino da Geologia destinado a alunos do curso de pós-graduação lato sensu em Gemologia, desenvolvido no Departamento de Geologia da Escola de Minas da Universidade Federal de Ouro Preto, nos anos de 2002 e 2003. A escolha da história da exploração aurífera em Ouro Preto como objeto privilegiado para a construção de atividades facilitou a compreensão das metodologias da produção do conhecimento científico geológico. Possibilitou trazer para o currículo de formação de professores de Geologia concepções que transcendem aquelas que são geralmente selecionadas nas abordagens, que apontam métodos e conteúdos sugeridos pelo professor ou professores que lhes ensinaram Geologia, ou seguir as sugestões de autores de livros-texto que abordam o tema. A utilização da história da exploração aurífera em Ouro Preto facilitou ao "futuro professor" a compreensão da importância de adquirir autonomia didática e fundamentação por meio de estudos do desenvolvimento histórico da Geologia, capacitando-os para utilizá-los como recurso para a seleção e organização deste conteúdo, obtendo ainda, da própria História da Ciência as sugestões de como ensinar.

Algumas questões permearam o planejamento do curso de Metodologia de Ensino da Geologia. Os alunos do curso são geólogos, engenheiros, geógrafos, químicos etc., com experiências anteriores muito diferenciadas em relação ao conhecimento geológico. No planejamento e execução do curso para esses alunos, que serão em potencial professores de Geociências , seja no curso secundário, seja nos semestres iniciais dos cursos superiores, optamos por privilegiar os conhecimentos da História da Geologia e, principalmente, da história da exploração aurífera em Ouro Preto, como recurso para criar estratégias didáticas.

\section{O CURSO DE METODOLOGIA DE ENSINO DA GEOLOGIA E SUA FUNDAMENTAÇÃO TEÓRICA}

Este curso destinado a alunos do curso de pós-graduação lato sensu em Gemologia, atualmente desenvolvido no departamento de Geologia da Escola de Minas de Ouro Preto da UFOP, complementa estudos específicos desta área, atendendo à legislação pertinente a estes cursos. Com uma carga horária de 60 horas/semestrais, acontece com alunos de formação universitária muito diferenciada quanto ao conhecimento geológico. Planejar um curso para estes alunos, que poderão vir a ser no futuro, professores de Geociências , remete-nos aos fatos de que o ensino de Geologia deveria procurar três tipos de aprendizagem, conforme nos assinala
Pedrinaci (1996, p. 2) ao parafrasear Hodson (1994):

1. a aprendizagem da Geologia, adquirindo e desenvolvendo os conhecimentos teóricos e conceituais necessários;

2. a aprendizagem sobre a natureza da Geologia, desenvolvendo um entendimento da natureza e os métodos desta Ciência, sendo consciente das interações complexas entre a Geologia e a sociedade;

3. a aprendizagem da prática da Geologia, desenvolvendo os conhecimentos técnicos sobre a investigação e a resolução de problemas geológicos que permitam o fazer Geologia.

Articular estas três necessidades básicas durante o planejamento das atividades em sala de aula e/ou no campo requer do futuro professor uma fundamentação teórica que o auxilie a montar estratégias pedagógicas efetivas.

As primeiras questões que surgem ao se pensar em um curso são:

a. Qual conteúdo será escolhido e como o mesmo poderá ser encadeado?

b. Que estratégias podem ser montadas para que a compreensão dos alunos seja efetiva?

c. Como levar os alunos a refletirem sobre como este conhecimento é gerado e de que maneira ele é validado ou refutado?

A tentativa de respostas para estas questões cria para o professor um leque de opções que vão desde reproduzir os conteúdos e os métodos utilizados pelo seu professor quando cursou Geologia na faculdade, ou seguir a sugestão do autor do último livro-texto que aborda o tema. Pode ainda o professor procurar adquirir certa autonomia didática e fundamentação através de estudos do desenvolvimento histórico das Ciências e utilizá-los como recurso para a seleção e organização deste conteúdo e obter da própria História da Ciência as sugestões como ensinar.

Autores como Collins e Shapin (1989), Galdabini e Rossi (1993), Pedrinaci (1994), Compiani e Gonçalves (1996) e Praia (1996) apontam o uso da Filosofia, da Sociologia e da História da Geologia no ensino, como um dos caminhos que auxiliaria o professor de Geologia a adquirir autonomia no planejamento das atividades didáticas futuras.

Ao referir-se à educação científica, Thomas Khun (1962, p. 56) ressalta que a educação científica se caracteriza por se fazer através de manuais, “obras escritas especialmente para estudantes”, o que não é muito comum em outros campos de atividade criativa. E que ao longo do curso, raramente, o aluno é posto diante do problema de conduzir um projeto de investigação, ou colocado ante os produtos diretos da investigação conduzida por outros - isto é, “as comunicações profissionais que os cientistas escrevem para os seus 
colegas”. Para Khun (1962, p. 57), “as coleções de textos 'originais' jogam um papel limitado na educação científica”.

Com relação à técnica de apresentação dos assuntos, mostra que os manuais científicos não chamam os estudantes a resolver ou discutir a diversidade de técnicas que a experiência colocou à disposição para a resolução dos problemas da vida profissional. Pelo contrário, desde o início apresentam "soluções concretas de problemas que a profissão aceita como paradigmas, e então pede-se a eles que com lápis e papel ou servindo-se dum laboratório, resolvam por si mesmo problemas modelados à semelhança, na substância e no método, que o livro lhes deu a conhecer" (Khun, 1962, p. 58).

Ainda ressalta que embora o desenvolvimento científico seja rico em novidades que se sucedem, a educação científica continua a ser uma iniciação "relativamente dogmática” a uma tradição preestabelecida de resolver problemas, para a qual o estudante não é convidado e não está preparado para apreciar. Ressalta ainda que:

“A educação sistemática dos manuais não existia em nenhuma parte e em nenhuma ciência (exceto talvez a Matemática elementar) até o começo do século XIX. ...Eram os feitos científicos descritos em livros que todos os praticantes num dado campo conheciam e admiravam, feitos que davam os modelos para as suas próprias investigações e os padrões para avaliar os seus próprios resultados. A physica de ARISTÓTELES, o Almagesta de PTOLOMEU, Os Principia e a Optiks de NEWTON, a Eletricidade de FRANKLIN, a Química de LAVOISIER, e os Princípios de Geologia de LYELL" (Khun, 1962, p. 58-59).

São obras que serviram para a definição de problemas e métodos de investigação para gerações de praticantes e juntamente com outros escritos tiveram "a mesma função que têm hoje os manuais de uma ciência” (Khun, 1962, p. 59).

Desta forma, considerando a importância que os textos originais possam representar na formação científica de jovens, a intenção maior do curso de Metodologia de Ensino passou a ser a de dar oportunidade à fundamentação teórica para que o futuro professor obtivesse as informações essenciais para conceber, no momento, durante o curso e para, futuramente, transmitir pela sua prática docente a seus alunos, uma visão de Geologia que não obscureça “como ela é construída”, como sugere Pedrinaci (1994).

\section{O uso da História das Ciências e a formação docente}

Para introduzir o tema, na primeira fase do curso, foram trabalhados textos, em sala de aula, que abordam a questão da História da Ciência e o ensino de Ciências. Textos estes na maioria lidos e discutidos na disciplina "História da Geologia e Ensino”, cursada pelo autor no curso de pós-graduação do DGAE/IG - UNICAMP, em 2001. Dentre os textos discutidos no curso, Matthews (1994) apresenta uma revisão sobre as relações entre História, Filosofia e Sociologia da Ciência, currículo, formação de professores e processos de aprendizagem, descrevendo diversas experiências educativas em várias partes do mundo. Este trabalho é um marco importante quando se pensa na formação tanto de jovens cientistas quanto na formação de cidadãos comuns.

Questões foram feitas, cuja reflexão serviu de base para a discussão dos propósitos do curso, como as que nos levaram a refletir sobre a realidade em que se dá o ensino superior de Geologia no Brasil, onde não é difícil detectar a existência de uma forte ênfase em atividades docentes que procuram dotar os egressos de habilidades e competências próximas da de um cientista.

O texto, traduzido por Sílvia Figueirôa, de Collins e Shapin (1989), enfatiza que as primeiras questões a que somos remetidos quando pensamos na educação científica de jovens do ensino secundário ou nos primeiros semestres da universidade é sobre o propósito de tal ação. Formar cientistas? Formar cidadãos? A opção por uma proposta exclui a outra? A discussão desta temática não é prerrogativa apenas nossa. Sugerem os autores, uma mudança neste enfoque para o ensino de Ciências, tendo por base a familiaridade que tem com os padrões em vigor na Grã-Bretanha e nos Estados Unidos.

Quando pensamos na realidade e associamos o lugar que a Ciência e, principalmente, a Geologia ocupa nos diversos processos de decisão, do cidadão comum, em nosso país, defrontamos com um cenário que nos remete a exigir um cidadão mais participativo, que na maioria das vezes abdica de seus direitos, porque desconhece, e ao desconhecer delega em favor de outros. A Ciência não está exercendo influência na vida dos cidadãos e nem os ajudando a exercer sua cidadania plena.

O ensino de Ciências pautado enfaticamente no relato da prática científica transmite para os futuros professores uma visão idealizada de Ciência, que ao fazerem uso da História da Ciência a imaginam como uma seqüência de fatos exitosos, praticados por homens “fora do comum”. Esta visão herdada passa a permear o ensino de Ciências que se converte numa sucessão e acumulação de fatos bem sucedidos, que para os alunos receptores passam a funcionar como dogmas.

Thomas Khun (1962), ao se referir aos manuais escritos para os estudantes, acrescenta, ainda, que: "as coleções de 'textos originais` jogam um papel limitado na educação científica”. E que: “igualmente o estudante de ciência não é encorajado a ler os clássicos da história do seu campo”.

Borrego e outros (1996) afirmam que a História da Ciência deve ser utilizada para orientar o tratamento metodológico através de textos históricos, uma vez que "oferece a 
possibilidade de propor os problemas e questões de maneira gradual, seguindo o desenvolvimento histórico dos conceitos".

Esta sugestão é que foi acatada. A elaboração de nossa proposta ao abordar no curso, o tema: “a exploração do ouro em Ouro Preto” apoiou-se em textos históricos relativos ao tema. Como recurso didático, visou orientar o futuro professor na reflexão sobre as características da atividade científica, para que formasse uma idéia mais adequada da Geologia e dos cientistas e assim o entendimento de como a Geologia é construída. Dessa forma o professor em potencial poderia estabelecer algumas relações entre a Geologia e a sociedade. Nossos objetivos foram além e pretenderam criar situações para que os alunos do curso pudessem reavaliar suas concepções sobre a origem do ouro, a partir de leituras críticas de alguns textos históricos, e ainda compreendessem conceitos científicos complexos e valorizassem seu significado e utilidade (Pedrinaci, 1994).

\section{A história da exploração aurífera em Ouro Preto}

Planejar um curso para estes alunos, professores de geologia em potencial, remete-nos também a algumas questões que julgamos essenciais quando pensamos no professor, como agente educativo e mais, especificamente, como mediador, quando aborda como conteúdos curriculares conhecimentos científicos e sua respectiva metodologia.

Como mediadores é também relevante que compreendam o seu papel de articuladores, de criadores de contextos de aprendizagem que sejam efetivos.

Como mediadores específicos de conhecimentos geológicos, é possível através de fundamentação teórica e a partir de estudos de filósofos, sociólogos e historiadores da Ciência, refletir sobre como é produzido o conhecimento geológico e planejar criticamente o ensino a ser empreendido.

De acordo com a sugestão de Galdabini e Rossi (1993), que usam papers históricos no ensino superior de Física, aliado à necessidade de experimentar junto aos alunos do curso, tanto em sala de aula quanto nos arredores de Ouro Preto, os três tipos de aprendizagem fundamentais salientados por Pedrinaci (1996), foi planejada uma unidade de ensino no curso com o tema: “A História da Exploração Aurífera em Ouro Preto e a Formação de Professores”.

Para isso foram escolhidos dois textos históricos que abordam o tema “Exploração Aurífera em Ouro Preto”, para serem trabalhados com os alunos. O primeiro deles foi produzido na virada do século XVIII para o XIX e o segundo do final do século XIX. O texto mais antigo foi extraído do trabalho de Clarete Paranhos da Silva, que estudou a obra do mineralogista José Vieira Couto, 1798 - 1805. Numa das “memórias” do autor é relatada sua "viagem de estudos na região das lavras de ouro nas cercanias de Vila Rica”, atual Ouro Preto. O segundo texto, do final do Século XIX, foi extraído do livro do Professor Paul Ferrand, que lecionou Exploração das Minas e Metalurgia na Escola de Minas. Seu livro “L’or à Minas Gerais” foi publicado em 1894.

Em sala de aula, os alunos fizeram leituras orientadas a partir de um roteiro elaborado pelo professor que priorizava questões que os levassem a refletir sobre as características da atividade científica praticada pelos dois autores dos textos selecionados. Tais questões foram:

a. Quais foram os procedimentos científicos utilizados para construir os conhecimentos geológicos por eles divulgados?

b. O papel da investigação levada pelos autores estava aliado à resolução de problemas de natureza social e/ou econômica?

c. Os textos deixam transparecer que os cientistas tinham uma visão global acerca do funcionamento da Terra?

O quadro a seguir sintetiza os principais pontos analisados para os dois textos:

\begin{tabular}{|c|c|c|}
\hline \multirow{2}{*}{ Pontos analisados } & \multicolumn{2}{|c|}{ Autores } \\
\hline & José Vieira Couto (1801) & Paul Ferrand (1894) \\
\hline \multicolumn{3}{|l|}{ Procedimentos científicos utilizados } \\
\hline • Observação & $\mathrm{x}$ & $\mathrm{x}$ \\
\hline • Medição & & $x$ \\
\hline - Análise de dados & & $x$ \\
\hline • Classificação & $\mathrm{X}$ & $\mathrm{X}$ \\
\hline - Elaboração de hipóteses & & $\mathrm{x}$ \\
\hline - Controle de variáveis & & $x$ \\
\hline • Contrastação & $\mathrm{x}$ & $\mathrm{X}$ \\
\hline O papel da investigação & Econômico & Econômico \\
\hline Visão global acerca do funcionamento da Terra & $\mathrm{x}$ & \\
\hline
\end{tabular}


O texto de José Vieira Couto (1801) observa e descreve as montanhas: "Este grande valle, que tem seus princípios no alto da Serra de Villa Rica, que olha para o poente, estende-se por longo espaço de terras”.

Observa e define a constituição das montanhas: "São montes sem camada; abaixo da crosta de humus vê-se uma substância talcosa em folheto chamada piçarra, substância esta que compõe todo o monte. Correm no meio dela veios de quartzo, que são os veeiros. A piçarra está disposta em grandes montões e não em camadas oblíquas ou perpendiculares".

Classifica e compara: "Em seu aspecto exterior eles conformam-se em tudo com os montes primitivos de Lehmann, ou com os montes de primeira ordem de Buffon, são altíssimos, ladeirentos, e pela maior parte encadeados".

Mostra ter concepção de que os processos geológicos ocorrem em um tempo medido em milhões de anos: "Estes dois valles continuados dividem em duas metades, e ao correr, o cume da serra, cuja divisão é o effeito insensível no fim dos séculos, mas que com a marcha de milhares de milhões d'elles apparece então grande e admirável...".

Mostra que o papel da investigação está aliado à resolução de problemas econômicos: "Estas observações são feitas sobre o território ao Nascente da Grande Serra, que é o mais montuoso d'esta capitania, e onde existem as lavras de ouro. ...Os montes da terceira classe de Lehmann, como montes pouco interessantes, não merecem ser aqui considerados".

A visão de conjunto acerca do funcionamento da Terra está expressa na teoria de Lehmann (1748) sobre a formação das montanhas:

“Três classes (ouçamos) há de montes na natureza, a primeira dos chamados primitivos: estes são muito mais altos que os outros, seus declives mui tezos, precipitados, e seguem pela maior parte em serras; o seu interior é formado de camadas oblíquas ou perpendiculares, espessas, e que vão ao centro da Terra; é cruzado de veeiros, e estes pela maior parte ricos; certos metais e certos mineraes acham-se com preferência mais n'estes montes, que em outros; são tão antigos quanto a Terra, e foram creados com ella. A segunda classe encerra os montes mais baixos, de declives mais ao laçante, isolados; suas entranhas se compõem de camadas horizontaes, delgadas, muitas, e que todas se vão terminar aos lados dos montes primitivos, dos quaes lhes vem os metaes que contém em si, e são mais pobres todavia que elles; foram creados pelas águas do dilúvio. A terceira classe se compõe de pequenos montes, que deveram suas origens a uma revolução parcial do nosso globo, como vulcões, aos terremotos e algumas inundações” (p. 121).
O trabalho de Paul Ferrand (1894), observa, descreve, e mede os afloramentos das minas da região de Ouro Preto:

"No interior da mina os últimos trabalhos permitiram reconhecer o filão num comprimento de quase 700 metros segundo a direção e 450 metros em profundidade, segundo o mergulho. A céu aberto, os afloramentos se alteram na margem direita ao longo do ribeirão do Carmo, desde a ponte de Passagem até Mariana, onde desaparecem sob uma camada de aluviões que forma o leito do rio, para reaparecerem do outro lado, no flanco escarpado de um contraforte da Serra de Ouro Preto, chamada do Morro Santana” (p. 221).

Ao descrever sugere que há uma continuidade lateral dos filões auríferos e que para a sua caracterização e reconhecimento é necessário compreender a sua disposição espacial:

"A ordem de sucessão dos terrenos que o encaixam é a seguinte: na base, nas partes mais profundas, reconhecidas até hoje, ocorrem micaxistos quartzozos; seguem-se, para cima, os quartzitos xistosos encaixantes do filão, depois os xistos criptocristalinos e por fim, na parte superior, os sideroxistos, ou itabiritos, e os xistos argilosos vermelhos, recobertos na superfície por uma crosta de canga mais ou menos dura” (p. 222).

Generaliza correlacionando as seqüências rochosas que encaixam a mineralização e definindo os constituintes minerais do filão que caracterizam o minério:

“A jazida é recoberta em toda essa extensão por uma camada de vários metros de itabiritos, com uma crosta de canga na superfície: além disso, aí se encontram os principais elementos do minério de Passagem. Compõese, de fato, de quartzo branco, contendo ouro na pirita arsenical, turmalina e pirita magnética. Por esses motivos, tem-se tudo para julgar que as minas de Passagem e Morro Santana pertencem ao mesmo filão” (p. 228).

Reforçando os procedimentos científicos utilizados para a descrição do jazimento aurífero recorre à linguagem visual: “...perto da ponte de Passagem... as jazidas de um lado e outro do rio pertencem ao mesmo filão. Esta era também a opinião do barão de Eschwege, como se pode constatar pelo corte da jazida de Passagem, por ele desenhado" (p. 229).

Ressalta a importância de descrever o momento da mineralização em relação às seqüências descritas e sintetizadas visualmente. A superposição dos filões, que cortam as camadas de Itabiritos mais jovens, é uma intersecção de estruturas: 
“Todavia, nas explotações do Morro de Santo Antônio, há uma particularidade a notar:... mineradores tratavam também os itabiritos, que deveriam conter, nesse caso, injeções de quartzo aurífero; isto explicaria de maneira mais racional seu sistema de explotação a céu aberto. Essa injeção de quartzo seria, portanto, posterior aos itabiritos e, por conseqüência, ao filão que injetou os quartzitos” (p. 230).

Estas foram as características das atividades científicas dos dois autores, Vieira Couto e Ferrand, que em sala de aula foram destacados. No campo, nos arredores de Ouro Preto, ampliamos a discussão a respeito dos atributos necessários para que um aluno iniciante pudesse apoderarse dos métodos básicos da Geologia. Além deste ponto, discutimos, no campo, quais seriam os conceitos básicos que dariam ao estudante condições de continuar aprendendo Geologia.

Foi elaborado um roteiro de campo, que tinha como ponto inicial de observação, o Morro do Cachorro, localizado no Parque do Itacolomi. Neste local, no alto de um morro com aproximadamente 1.500 m de altitude, com um plano de visão que coloca na frente dos observadores a Serra de Ouro Preto, foi possível reconstruir com os alunos as imagens descritas por José Vieira Couto em seu texto sobre as montanhas, os vales e a ocorrência aurífera da região.

A escala de observação expressa nos escritos de Couto se aproxima da que os observadores (alunos e professor) estavam tendo naquela altitude $(1.500 \mathrm{~m})$. Nesta escala, os caracteres externos dos montes, ("altíssimos, ladeirentos, e pela maior parte encadeados”), ao serem agrupados, servem de referência para que o autor generalize e conclua por definir as montanhas como sendo as mesmas dos montes primitivos de Lehmann.

Este recurso do cientista, que faz uso da analogia com uma teoria, nos mostra o quanto as observações no campo são estratégicas para a realização de "operações intelectuais, como raciocínios indutivos, dedutivos que se combinam para selecionar e organizar observações e interpretações para aplicar informações de diversas fontes (supostos, hipóteses, teorias)" (Compiani e Gonçalves, 1996, p. 42).

Neste local, também foi possível ampliar a discussão a respeito do cientista José Vieira Couto e do momento histórico em que viveu, final do Século XVIII, época em que os estudos sobre a Terra estavam em pleno desenvolvimento, em boa parte para atender às demandas da Revolução Industrial. Conhecer os minerais de valor econômico tornouse fundamental para as sociedades européias. O que fez com que os estudos se focalizassem nas áreas reconhecidamente ricas e se desenvolvessem com um caráter muito pragmático, como esclarece Da Silva (2002, p. 123) ao citar Rudwick (1996).
E neste ponto, Couto mostra ser um cientista de seu tempo. O trabalho que executa nas minas da Capitania é um esforço do Reino Português em restaurar as suas economias e, conta nesta época, não só com a colaboração de Couto, mas de outros brasileiros que haviam estudado Filosofia Natural durante suas passagens pela Universidade de Coimbra, Da Silva (2002). Foi na Universidade que Couto entrou em contato com a prática e as teorias, que ele adapta a sua realidade.

Esta discussão, no campo, foi frutífera para mostrar aos alunos que nossa postura naquele momento de análise, de forma alguma deveria se direcionar para um "julgamento" dos procedimentos científicos de Couto, tendo por referência os nossos conhecimentos atuais a respeito da geologia da região. Mas que, como homem de sua época, o seu trabalho respondia a perguntas que eram próprias para o momento em que viveu. Desta forma, foi possível apontar que a partir destes primeiros trabalhos há um desenvolvimento científico, cujos conceitos básicos da Geologia que surgiram a partir daí, responderam a questões colocadas em outros momentos, em que a sociedade demandava por eles. Uma visão de cientista e de Ciência vinculada ao contexto sócio-político-econômico pôde ser desenvolvida com os alunos.

Posteriormente, nos domínios da Serra de Ouro Preto, dentro de um plano de observação dos afloramentos, em escala mesoscópica, foram trabalhadas com os alunos quatro localidades: Taquaral; boca da mina de Mata Cavalos; interior da mina da Passagem e canyon de Passagem.

Para este trabalho foi proposto um roteiro que serviu de guia para que os alunos, ora individualmente, ora em pequenos grupos, observassem e discutissem:

1. a composição material dos corpos rochosos, nos quais procurou-se evidenciar os diferentes tipos de rochas e as características dos minerais presentes;

2. a representação gráfica dos corpos, evidenciando seus limites e características mais marcantes, procurando também representar no desenho a forma destes corpos.

Na entrada da galeria de uma exploração antiga, no Taquaral, dentre as litologias existentes, a que mais chama a atenção do aluno, à primeira vista, é o filão de quartzo branco leitoso intercalado entre sericita-biotita-quartzo xistos e Itabiritos, até mesmo pelo contraste de cores muito diferentes entre o filão branco e as encaixantes mais escuras. Aqui, neste local a constituição mineral do filão de quartzo serviu de base, não só para evidenciar quais são os recursos técnicos necessários para a compreensão da assembléia de minerais que o compõe, mas também um local fértil para elaborarmos as hipóteses que serviram de base para continuarmos compreendendo o modelo de Ferrand. 
Logo no início, foi relembrado que para Ferrand, os filões: "compõe-se, de fato, de quartzo branco, contendo ouro na pirita arsenical, turmalina e pirita magnética".

A primeira dificuldade exposta pelos alunos foi o fato de não encontrarmos no afloramento toda a assembléia mineral descrita pelo autor. Estavam presentes, o quartzo branco e a arsenopirita (pirita arsenical para Ferrand). Faltavam a turmalina e a pirita magnética (pirrotita). A ausência de dois minerais que caracterizavam os filões, na maneira como tinham sido descritos por Ferrand, levou os alunos a construírem as hipóteses possíveis para o acontecido: “Ou neste local ocorre apenas estes dois minerais característicos, ou se trata de um filão diferente do descrito por ele".

Ficou evidente para todos que não só era importante ter uma técnica e instrumentos para caracterizarmos os minerais, mas também comparar, fazer analogia com o modelo de Ferrand. O procedimento científico, de observar, classificar, comparar, usado por José Vieira Couto, em outra escala de observação, em outro momento histórico, o aproxima de Paul Ferrand, pela utilização de procedimentos científicos comuns na geração de conhecimento geológico. O que fortaleceu, junto aos alunos, a idéia de que para a Geologia, a analogia é um método estratégico de procedimento intelectual, como assinalam Compiani e Gonçalves (1996), citando Gruza e Romanovsky (1975).

As hipóteses criadas neste afloramento deveriam ser testadas nas próximas paradas. As informações obtidas seriam contrastadas às novas e, assim sucessivamente, a comparação e analogia seriam os recursos a serem utilizados pelos alunos no processo de apreensão das informações básicas necessárias para continuar aprendendo Geologia.

Na boca da galeria da mina de Mata Cavalo e no interior da mina de Passagem de Mariana, a assembléia de minerais pôde ser completada e a seqüência de rochas, por fim, ser comparada com os desenhos feitos por eles e o modelo apresentado por Ferrand, tanto em "linguagem verbal", quanto em "linguagem visual".

Em superfície, após a saída da mina subterrânea - hoje aberta ao turismo - no local descrito por Ferrand, como sendo o local ideal para ser observada a continuidade lateral do filão de quartzo e de suas rochas encaixantes, foi retomado o texto de Ferrand e o corte esquemático feito por Eschwege, no início do século XIX.

Neste local, tendo à frente o canyon representado no perfil esquemático de Eschwege, redesenhado por Ferrand, no final do século XIX e reproduzido em Ferrand (1998, p. 221), foi discutida a importância da experiência de campo e da linguagem visual para o aluno iniciante da Geologia. Foi feita uma revisão dos procedimentos necessários para chegarmos à compreensão dos princípios básicos da superposição dos estratos, da continuidade lateral e por fim, sobre as operações necessárias para o estabelecimento de correlações.

\section{CONSIDERAÇÕES FINAIS}

A história da exploração aurífera em Ouro Preto como objeto de estudo possibilitou trazer para os alunos do curso de Metodologia de Ensino da Geologia fundamentos e conceitos da Geologia imprescindíveis para o futuro professor desta Ciência. O desenvolvimento deste estudo criou espaço, no curso, para a reflexão sobre o papel da Epistemologia e História da Geologia enquanto fundamento teórico para a formação do professor desta Ciência.

O objetivo maior era contribuir para que os professores em formação se tornassem mais conscientes de suas ações como mediadores da construção da atividade científica, facilitando, portanto, sua atuação como "sujeitos de procedimentos didáticos” (Praia, 1996). Este autor relata que as concepções dos professores sobre a Ciência influem sobremaneira no que ensinam, na maneira como o fazem e no significado que atribuem ao conteúdo e que, portanto, ao trazer a Epistemologia e a História da Geologia para o campo da Didática é possível criar suportes e contribuições na reorientação da prática docente.

Foi possível discutir com os alunos que o tema "mineralização aurífera” foi alvo de questões, em momentos diferentes, oriundas da sociedade que os cientistas faziam parte. Enquanto homens de seus tempos expressam valores das sociedades de suas épocas. Foi possível discutir Ciência como constructo social.

Procurou-se construir com a atividade uma imagem da Geologia que levasse o aluno a refletir sobre a especificidade do seu pensamento e da maneira de como é produzido seu conhecimento. Foi possível discutir como o pesquisador da Geologia observa, organiza e explica a realidade de maneira diferenciada de outras Ciências da Natureza. Foi possível reconhecer seu caráter histórico e sua natureza interpretativa.

No campo, o estudo se revelou eficiente na demonstração da forma específica de obter informações e relatar seus resultados e favoreceu a discussão a respeito da História da emergência da Mineralogia (Guntau, 1984) e Geognosia a partir da História Natural, que no tempo de José Vieira Couto e do Barão Eschwege, alcançam o status de conhecimento científico.

A importância da imagem tanto na concepção de um modelo teórico, quanto para a apresentação de resultados ficou evidenciada através da "linguagem verbal” do modelo de Lehman, narrado por Couto, quanto pela "linguagem visual” do perfil esquemático de Eschwege apresentado por Ferrand.

A emergência das Ciências Geológicas se dá concomitantemente com o uso pelos mineralogistas da época do recurso visual, do instrumental cartográfico. É importante que o professor de Geologia reconheça que "dominar o instrumental cartográfico é um dos passos para estruturar o conhecimento 
sobre a natureza" (Compiani e Gonçalves, 1996).

O desconhecimento pelo professor destas especificidades pode levar a uma prática didático-pedagógica que "oculta e distorce o sentido Epistemológico da disciplina”. Assim pensa Praia (1996), que o professor de Geologia deve "pensar e fazer didática da Geologia através da reflexão crítica e experimental do planejado, fazendo intervir as vertentes - epistemológica e histórica - como fundamentadoras da e para a ação”.

\section{REFERÊNCIAS BIBLIOGRÁFICAS}

BORREGO, M. J.; GARCÍA, R.; GUEDE, B.; MENÉNDEZ, E.; PACHECO, F. La utilización de la Historia de la Ciencia para trabajar problemas relacionados con los fósiles. Enseñanza de las Ciencias de la Tierra, v. 4, n. 1, p. 45-52, 1996.

COLLINS, R.; SHAPIN, S. Experiment, Science teaching, and the new History and Sociology of Science. In: SHORTLAND, M.; WARWICK, A. Teaching the History of Science. London: BSHS: Blackwell, 1989. p. 67-79.

COMPIANI, M.; GONÇALVES, P. W. Epistemología e Historia de la Geología como fuentes para la selección e organización del currículo. Enseñanza de las Ciencias de la Tierra, v.4, n.1, p. 38-45, 1996.

DA SILVA, C. P. O desvendar do grande livro da natureza: um estudo da obra do mineralogista José Vieira Couto, 1795-1805. São Paulo: Unicamp, 2002.

FERRAND, P. O Ouro em Minas Gerais. Belo Horizonte: Fundação João Pinheiro, 1998.

GALDABINI, S.; ROSSI, O. Using historical papers in ordinary Physics teaching at high school. Science \& Education, v. 2, p. 239-242, 1993.

HODSON, D. Hacía un enfoque más crítico del trabajo de laboratorio. Enseñanza de las ciencias, v.12, n.3, p. 299-313, 1994.

KUHN, T. S. The structure of scientific revolutions. Chicago: University of Chicago Press, 1962.

KUHN, T. S. A função do dogma na investigação científica. In: DEUS, J. D. (Org.). A crítica da ciência, sociologia e ideologia da ciência. Rio de Janeiro: Zahar, 1962.

MATTHEWS, M. R. Historia, Filosofía y enseñanza de las Ciencias: la aproximación actual. Enseñanza de las Ciencias, v. 12, n. 2, p. 255-277, 1994.

PEDRINACI, E. La Historia de la Geología como herramienta didáctica. Enseñanza de las Ciencias de la Tierra, v. 2, n. 2-3, p. 332-339, 1994.

PEDRINACI, E. Por Su Historia la conocerán. Enseñanza de las Ciencias de la Tierra, v. 4, n. 1, p. 2-3, 1996.

PRAIA, J. F. Epistemología e Historia de Ciencia: contribuciones a la planificación didáctica. La Deriva Continental. Enseñanza de las Ciencias de la Tierra, v. 4, n. 1, p. 30-37, 1996. 